\title{
Burning velocity measurement of lean methane-air flames in a new nanosecond DBD microplasma burner platform
}

\section{Citation for published version (APA):}

Elkholy, A., Shoshyn, Y., Nijdam, S., van Oijen, J. A., van Veldhuizen, E. M., Ebert, U., \& de Goey, L. P. H. (2018). Burning velocity measurement of lean methane-air flames in a new nanosecond DBD microplasma burner platform. Experimental Thermal and Fluid Science, 95, 18 - 26.

https://doi.org/10.1016/j.expthermflusci.2018.01.011

\section{Document license:}

TAVERNE

DOI:

10.1016/j.expthermflusci.2018.01.011

Document status and date:

Published: 01/07/2018

\section{Document Version:}

Publisher's PDF, also known as Version of Record (includes final page, issue and volume numbers)

\section{Please check the document version of this publication:}

- A submitted manuscript is the version of the article upon submission and before peer-review. There can be important differences between the submitted version and the official published version of record. People interested in the research are advised to contact the author for the final version of the publication, or visit the $\mathrm{DOI}$ to the publisher's website.

- The final author version and the galley proof are versions of the publication after peer review.

- The final published version features the final layout of the paper including the volume, issue and page numbers.

Link to publication

\section{General rights}

Copyright and moral rights for the publications made accessible in the public portal are retained by the authors and/or other copyright owners and it is a condition of accessing publications that users recognise and abide by the legal requirements associated with these rights.

- Users may download and print one copy of any publication from the public portal for the purpose of private study or research.

- You may not further distribute the material or use it for any profit-making activity or commercial gain

- You may freely distribute the URL identifying the publication in the public portal.

If the publication is distributed under the terms of Article 25fa of the Dutch Copyright Act, indicated by the "Taverne" license above, please follow below link for the End User Agreement:

www.tue.nl/taverne

Take down policy

If you believe that this document breaches copyright please contact us at:

openaccess@tue.nl

providing details and we will investigate your claim. 


\title{
Burning velocity measurement of lean methane-air flames in a new nanosecond DBD microplasma burner platform
}

\author{
A. Elkholy ${ }^{\mathrm{a}, \mathrm{c}, *}$, Y. Shoshyn ${ }^{\mathrm{a}}$, S. Nijdam ${ }^{\mathrm{b}}$, J.A. van Oijen ${ }^{\mathrm{a}}$, E.M. van Veldhuizen ${ }^{\mathrm{b}}$, U. Ebert $^{\mathrm{b}}$, \\ L.P.H. de Goey ${ }^{\mathrm{a}}$ \\ a Department of Mechanical Engineering, Eindhoven University of Technology, The Netherlands \\ ${ }^{\mathrm{b}}$ Department of Applied Physics, Eindhoven University of Technology, The Netherlands \\ ${ }^{\mathrm{c}}$ Department of Mechanical Engineering, Helwan University, Egypt
}

\section{A R T I C L E I N F O}

\section{Keywords:}

Plasma-assisted combustion

DBD

Microplasma

Burning velocity

\begin{abstract}
A B S T R A C T
This paper presents the initial characterization of a new burner design to study the effect of non-thermal plasma discharge on combustion characteristics at atmospheric pressure. The burner allows stabilizing an inverted cone flame in a mixture flowing through a perforated plate designed as a microplasma reactor. The design principle of the microplasma reactor is based on the dielectric barrier discharge scheme which helps to generate a stable nonthermal plasma discharge driven by nanosecond high-voltage pulses in the burner holes. The consumed power and pulse energy have been calculated from simultaneously measurements of current and voltage of the electrical pulses. Time-resolved measurements of direct emission spectra for nitrogen second positive system $\mathrm{N}_{2}(\mathrm{C}$-B) have been done to determine the rotational and vibrational temperatures of the plasma discharge. By fitting the spectra with SPECAIR simulation data, it was found that the rotational and vibrational temperatures are $480 \mathrm{~K}$ and $3700 \mathrm{~K}$, respectively, for the discharge in methane-air mixture with an equivalence ratio of 0.5 at atmospheric pressure. The influence of a high-voltage $(5 \mathrm{kV})$ pulsed nanosecond discharge on the laminar burning velocity of methane-air flame has been investigated over a range of equivalence ratios (0.55-0.75). The laminar burning velocity was calculated by the conical flame area method which has been validated by other published data. $\mathrm{CH}^{*}$ chemiluminescence image analysis has been applied to accurately determine the flame area. The results show an increase of the burning velocity of about $100 \%$ in very lean $(\Phi=0.55)$ flames as a result of the plasma discharge effect.
\end{abstract}

\section{Introduction}

In recent decades, great efforts have been performed to reduce $\mathrm{NO}_{\mathrm{x}}$ emissions from the combustion products of gas turbines, aircraft engines, industrial burners and automotive engines. These efforts include and are not limited to exhaust gas recirculation, staging combustion, catalytic converter, oxy-fuel combustion and lean premixed combustion. One of the most promising ways to burn in very lean conditions is to generate a sustainable source of reactive species in the combustion domain by the so-called 'plasma-assisted combustion'.

Plasma-assisted combustion has attracted a lot of attention over the last decades due to its capability to stabilize ultra-lean flames, decrease ignition delay time, extend flammability limits and increase the burning velocity $[1,2]$. A lot of fundamental research has been done to address different mechanisms by which non-thermal plasma enhances combustion characteristics.

Many types of power sources, like AC discharge [3], DC discharge
[4], microwave [5] and RF discharge [6], have been used to generate plasma discharges in combustion applications. Among all these types of plasma discharges, nanosecond-pulsed discharge is considered a very active source of highly energetic electrons and reactive species $[7,8]$. Moreover, the non-thermal nature of nanosecond-pulsed discharge helps to avoid excessive gas heating which leads to thermal $\mathrm{NO}_{\mathrm{x}}$ production.

In addition, the dielectric barrier discharge scheme (DBD) $[9,10]$ is considered as one of the most successful ways to reduce the chances of generating the undesired glow to arc transition, which is usually come along with the high-voltage pulses. The presence of a dielectric layer between the electrodes reduces the electric field generated by a given charge density. This helps to generate a uniform discharge distribution and reduces the chances of glow to arc transition for atmospheric pressure applications.

In this paper, we introduce a new burner platform that utilizes a dielectric barrier microplasma reactor to sustain a stable non-thermal

\footnotetext{
* Corresponding author at: Department of Mechanical Engineering, Eindhoven University of Technology, The Netherlands.

E-mail address: A.Elkholy@tue.nl (A. Elkholy).
} 


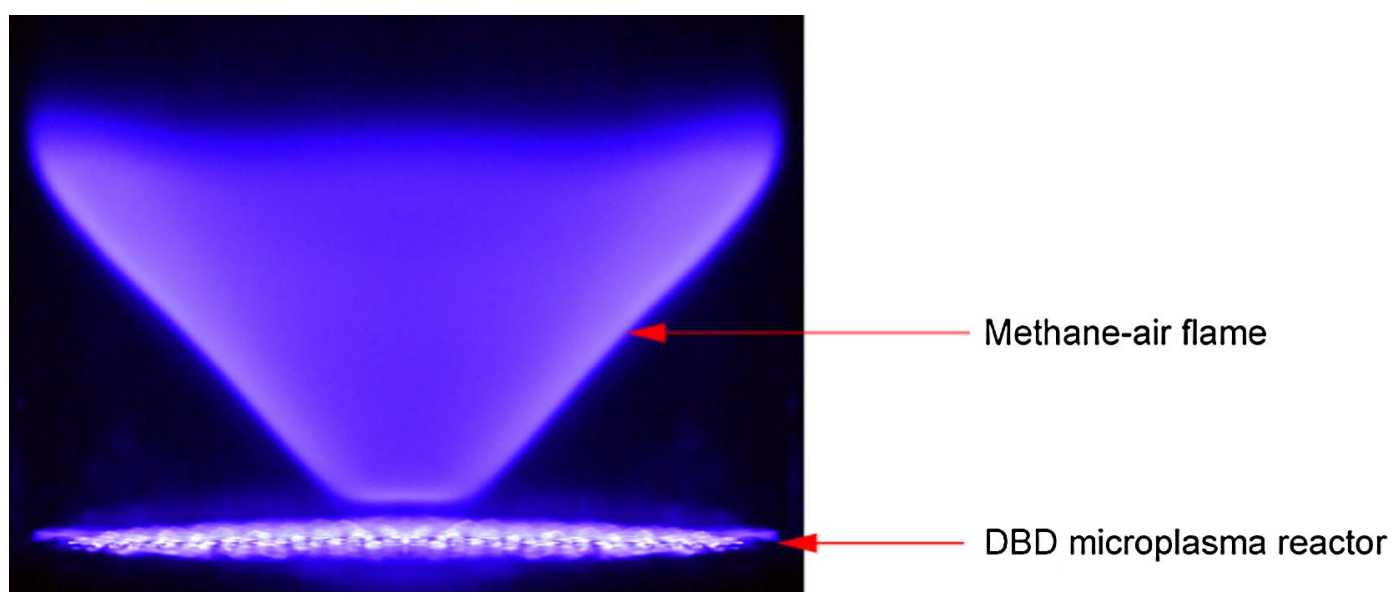

Fig. 1. Image of DBD microplasma burner and lean methane-air flame.

plasma discharge in all of the holes of a perforated burner plate using nanosecond high-voltage power source at atmospheric pressure. Fig. 1 shows an example of a methane-air flame stabilized above the perforated plate during the plasma discharge. By this way, we ensure a close interaction between plasma discharge and gas mixture before burning. The main goal of this setup is to study the effects of nanosecond highvoltage plasma discharge on burning velocity and combustion chemistry of methane-air flames at atmospheric pressure over a broad range of plasma and flame conditions.

This article will focus, first, on describing the microplasma reactor design and experimental setup, followed by electrical and thermal parameter measurements of the plasma discharge for methane-air mixture. Finally, the burning velocity of methane-air premixed flames at different equivalence ratios and plasma conditions have been investigated.

\section{Experimental setup}

\subsection{Microplasma reactor geometry}

As shown in Fig. 2, the reactor geometry is consisting of four layers of electrodes, each pair of electrodes (anode and cathode) can work separately or together. Cathode and anode electrodes are separated by a

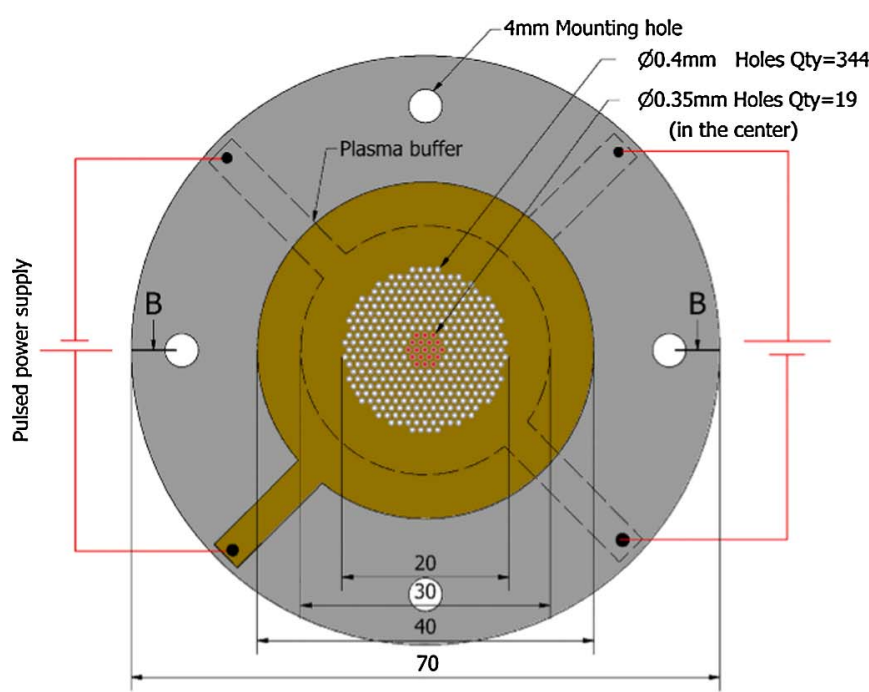

Plan view (A) dielectric material with a thickness of $0.36 \mathrm{~mm}$. The outer and inner electrodes are made of copper with a thickness of $18 \mu \mathrm{m}$ and $38 \mu \mathrm{m}$ respectively. The separation distance between the two inner electrodes is $0.6 \mathrm{~mm}$, while the total thickness of the reactor is $1.5 \mathrm{~mm}$. Two sets of hole diameters have been used. In the central part, there are 19 holes with a diameter of $350 \mu \mathrm{m}$ to anchor the flame in the central position and produce thereby inverted cone flames. Apart from the center, there are 344 holes with a diameter of $400 \mu \mathrm{m}$. All the holes are arranged in a hexagonal pattern with a pitch of $1 \mathrm{~mm}$. The effective area of the reactor is $314 \mathrm{~mm}^{2}$ with a blockage ratio of 86 percent.

A study of geometrical and electrical parameters has been performed to ensure minimum dielectric thickness that is capable to acquire a strong plasma discharge. The geometry has been designed such that most of the discharge to be located inside the holes instead of being on top or bottom surfaces of the reactor for better interaction with the flowing gas. The width and thickness of the embedded electrodes have been calculated to safely withstand the peak current of the discharge pulses which is $80 \mathrm{~A}$ for a duration of $10 \mathrm{~ns}$, as shown in Fig. 5. In this study,

Fig. 3 shows an example of the discharges in air at atmospheric pressure (left) and $50 \mathrm{mbar}$ (right). It can be noticed that, at atmospheric pressure, the discharge is concentrated as an annular ring around the wall of the holes near the cathode, while, at 50 mbar, the
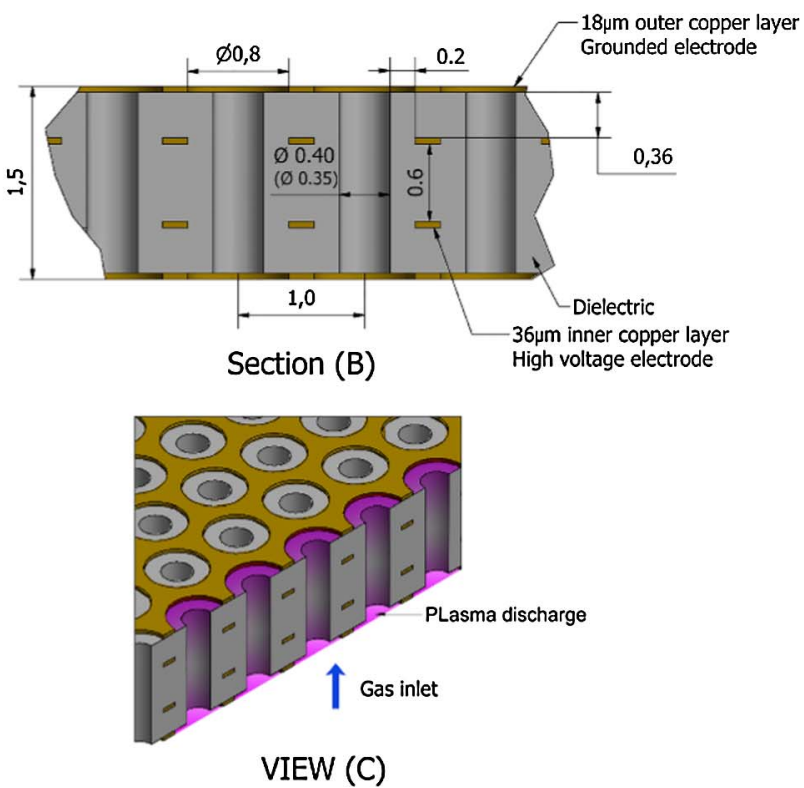

Fig. 2. Schematic of the DBD microplasma burner plate [all dimensions are in mm]. 


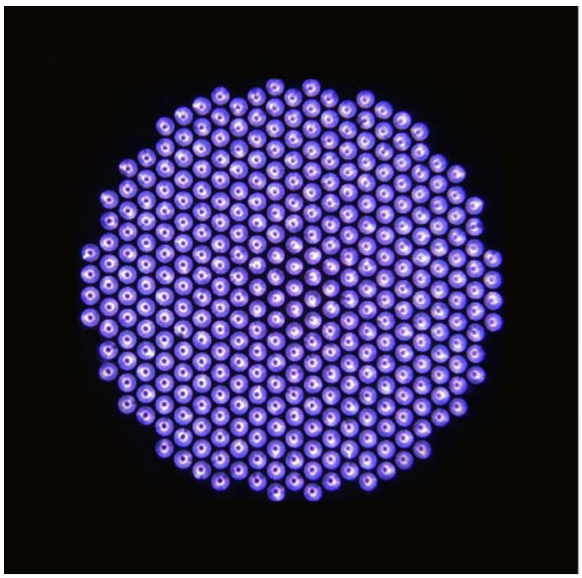

(a)

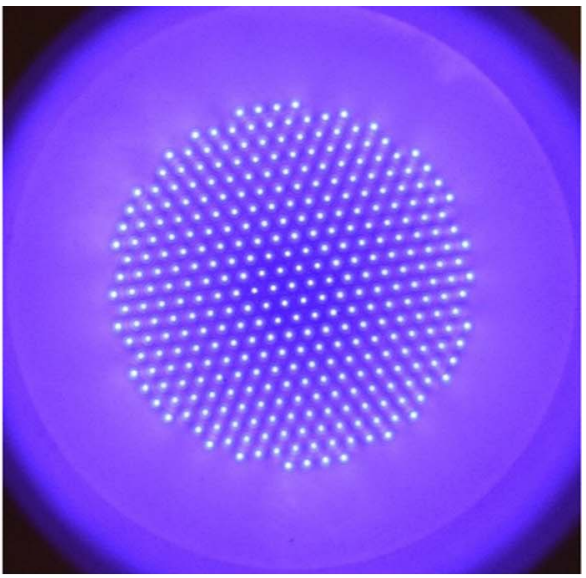

(b) discharge fills the whole volume of the holes and spreads far above the perforated plate.

The dielectric material is a composite material composed of woven electrical grade fiberglass with an epoxy resin. It has a dielectric constant $\mathrm{D}_{\mathrm{r}}$ of $4.17 \pm 0.05$ at $\left(1 \mathrm{GHz} / 23^{\circ} \mathrm{C}\right)$, a thermal conductivity of $0.4 \mathrm{~W} / \mathrm{m} \mathrm{K}$, a dielectric breakdown voltage of $50 \mathrm{kV}$, a thermal expansion coefficient of $14 \mathrm{ppm} /{ }^{\circ} \mathrm{C}$ and glass transition temperature of $180^{\circ} \mathrm{C}$. This material has a stable performance over a wide range of frequencies and temperatures as well as good machinability performance.
Fig. 3. Plasma discharge in the DBD microplasma reactor in air at (a) 1 bar (b) 50 mbar.

\subsection{Flow setup}

The schematic representation of the experimental setup is shown in Fig. 4. The burner consists of four main parts; the plenum chamber in the bottom, water jacket in the middle, microplasma reactor and quartz tube on top of the burner. The plenum chamber and the water jacket are made of steel and brass respectively. The plenum chamber creates a uniform flow towards the plasma reactor. The gas inlet is located at the bottom of the plenum chamber. A perforated plate, which is placed $20 \mathrm{~mm}$ from the bottom, works as a flow straightener. The holes in the perforated plate cover the entire area of the plate.

The holes are $1.0 \mathrm{~mm}$ in diameter and $2.0 \mathrm{~mm}$ in pitch. The reactor

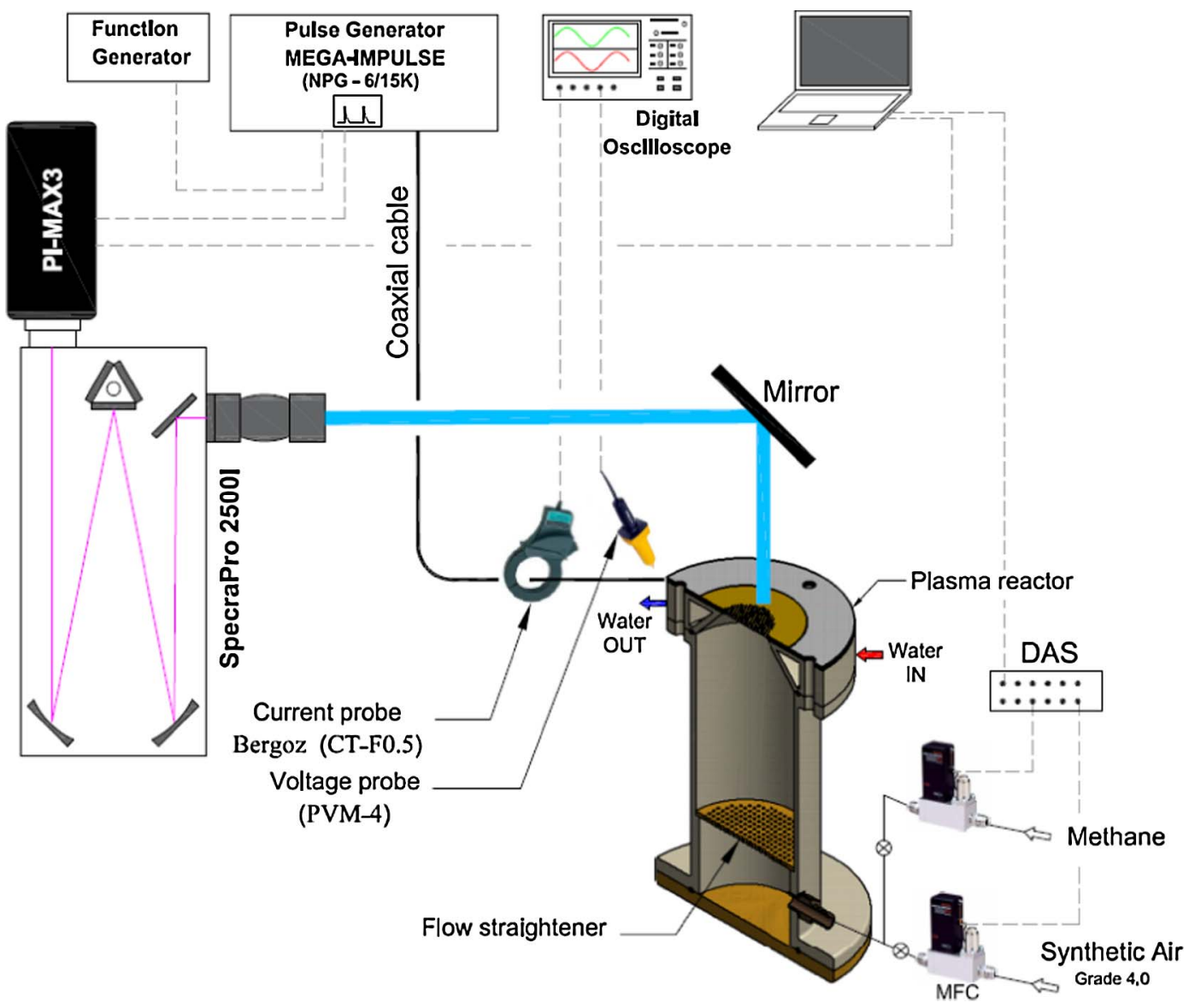

Fig. 4. Schematic of the experimental setup. 

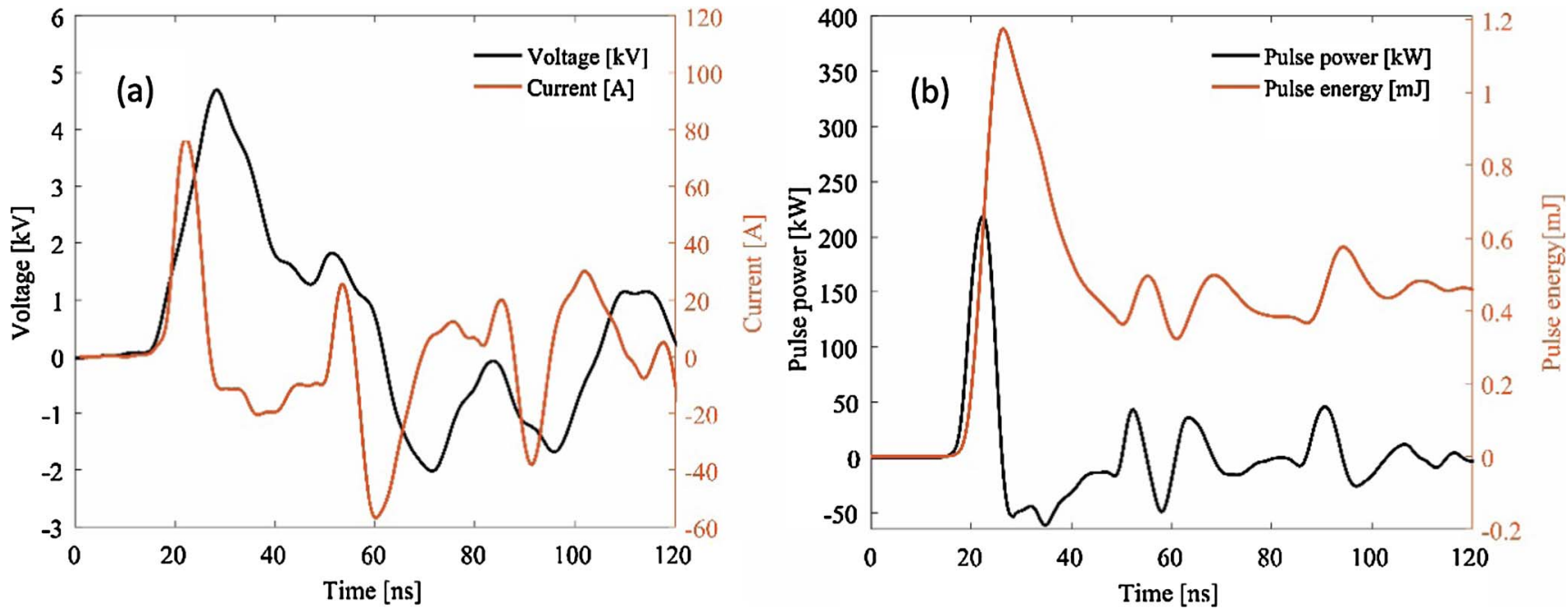

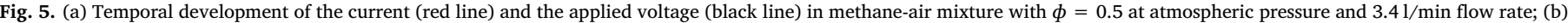

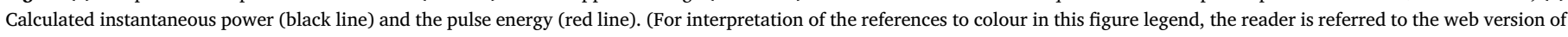
this article.)

temperature is controlled by means of a water jacket underneath of the microplasma reactor. The inlet and outlet of the water are connected to a thermostat to keep the water temperature at the pre-set value, up to $80^{\circ} \mathrm{C}$. A cylindrical quartz tube with an internal diameter of $22 \mathrm{~mm}$, a wall thickness of $2 \mathrm{~mm}$ and height of $100 \mathrm{~mm}$ is used to confine the combustion and to provide an optical access to the flame.

The air and methane flow are controlled by a mass flow controllers (MFC) which are connected to the computer via an RS232 serial line and communicates through Bronkhhost program. A cylindrical buffer vessel is placed before the MFC to damp any pressure fluctuations from the source. In addition, an air filter is installed just before the MFC to avoid gas contamination. To ensure purity, synthetic air grade 4.0 has been used.

\subsection{Optical emission spectroscopy}

The optical emission spectroscopic measurements have been performed with a SpectraPro 2500i spectrometer of a focal distance of $0.5 \mathrm{~m}$ fitted with three gratings; 300 (blazed at $300 \mathrm{~nm}$ ), 1800 (blazed at $200 \mathrm{~nm}$ ) and 3600 (blazed at $300 \mathrm{~nm}$ ) grooves/mm with an entrance slit of $20 \mu \mathrm{m}$. The emission spectra from the plasma discharge have been recorded using a 1024 x 1024 pixels ICCD camera (Princeton Instrument PIMax). The entire optical system is calibrated using a lowpressure pencil-type mercury calibration lamp model ORIEL 6035. An UV-Nikkor lens with $105 \mathrm{~mm}$ focal length and f/4.5 attached to the spectrometer entrance slit has been used to collect the emitted light from the plasma. The slit function of the spectrograph is approximately a Gaussian shape with equivalent FWHM (full width at half maximum) of $0.58 \mathrm{~nm}$ at 300 grooves/mm grating, $0.084 \mathrm{~nm}$ at 1800 grooves $/ \mathrm{mm}$ grating and $0.037 \mathrm{~nm}$ at 3600 grooves/mm grating.

Synchronization between the pulse signal and the ICCD camera was achieved by the triggering signal from the pulse generator. A $200 \mathrm{~ns}$ time delay has been observed between the pulse and the onset of the plasma discharge. This time delay comes from three sources; (1) the pulse generator delay, (2) signal delay due to the cable length ( $3 \mathrm{~m})$ and (3) the charging of the reactor capacitance.

\section{Results and discussion}

\subsection{Electric characteristics}

A non-equilibrium plasma has been produced by a Mega-Impulse semiconductor based pulse generator model NPG-6/15k. A series of electric positive polarity pulses of $4-7 \mathrm{kV}$ in amplitude at a matched load of $75 \mathrm{Ohm}$ or $10 \mathrm{kV}$ at open circuit, $10 \mathrm{~ns}$ in duration and $6 \mathrm{~ns}$ rise time is created at a pulse repetition frequency in the range of $0-10 \mathrm{kHz}$. Fig. 5 shows the current and applied voltage characteristics of the discharge in methane-air mixture with $\phi=0.5$ at atmospheric pressure for the electrode system shown in Fig. 2.

A data oscilloscope model Lecroy Waverunner 44MXi-A with a bandwidth of $400 \mathrm{MHz}$ has been used to simultaneously monitor the voltage and current wave signals. A $10 \mathrm{~V}$ and $100 \mathrm{~ns}$ pulse signal produced by a pulse generator model FY2102S is used to trigger the plasma generator. The voltage is recorded by a North Star high-voltage probe model PVM- 4 with a sensitivity of $1 \mathrm{~V} / 1 \mathrm{kV}$, a bandwidth of $120 \mathrm{MHz}$ and $2 \mathrm{~ns}$ rise time. The current through the electrodes is measured by a Bergoz current transformer model CT-F0.5 with a 1.75 ns rise time and a sensitivity of $0.5 \mathrm{~V} / \mathrm{A}$ voltage-to-current conversion located on the ground cable.

Fig. 5(a) shows the total current and voltage evolution for a single pulse of a single layer DBD microplasma reactor in methane-air mixture with $\phi=0.5$ at atmospheric pressure and $3.4 \mathrm{~L} / \mathrm{min}$ flow rate. As shown, the voltage signal has two peaks, the first one has a positive polarity and peak value of $5 \mathrm{kV}$, while the second one has a peak of $2 \mathrm{kV}$ with a negative polarity. The current signal has also the same behaviour with positive peak of $80 \mathrm{~A}$, and a negative peak of $50 \mathrm{~A}$. The full width at half maximum (FWHM) duration of each current signal is about 10 ns.

The instantaneous pulse power $P$ applied to the plasma is obtained by multiplying the measured voltage $V$ and the discharge current $I$ (black line in Fig. 5(b)). Then, the power is integrated over the pulse duration to get the energy deposited in the plasma discharge. As shown in Fig. 5(b), the total energy per pulse $E$ is about $0.45 \mathrm{~mJ} /$ pulse for $\phi=0.5$ at atmospheric pressure.

$E_{\text {pulse }}=\int_{t_{1}}^{t_{2}} I \cdot V d t$

To evaluate the effect of the fuel amount in the mixture on the discharge intensity, Fig. 6 shows the total pulse energy for different equivalence ratios, ranging from 0.5 to 0.75 , while keeping the voltage across the electrodes at $5 \mathrm{kV}$. As shown in the figure, by increasing the equivalence ratio from 0.5 to 0.75 , the total pulse energy decreases, slightly, from 0.45 to $0.42 \mathrm{~mJ} /$ pulse. A similar behaviour has been observed by Pilla et al. [11], where they found that the excited species are partially consumed, quenched or produced in a smaller amount by increasing the amount of the fuel in the mixture. 


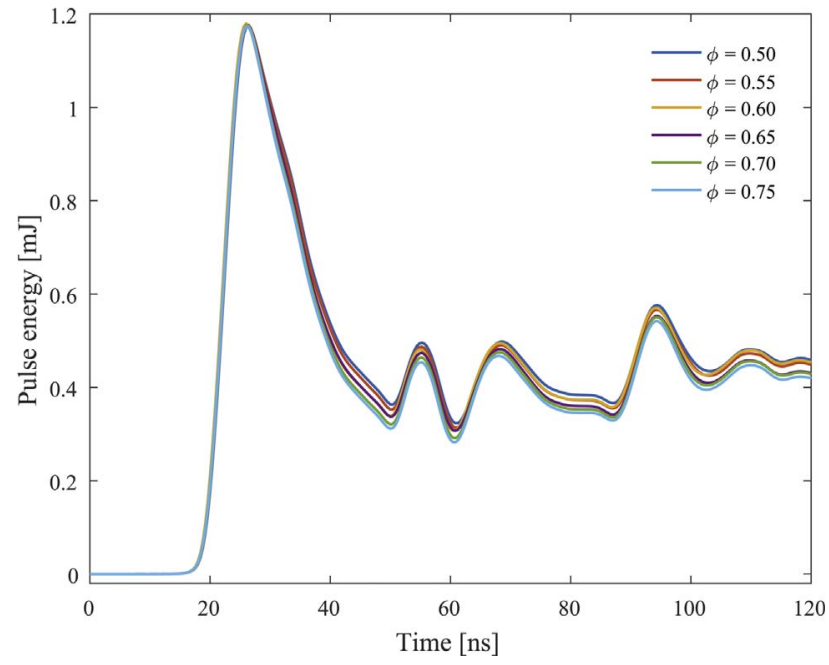

Fig. 6. The discharge energy per pulse for methane-air mixture for different equivalence ratios, at atmospheric pressure and $3.4 \mathrm{l} / \mathrm{min}$ flow rate.

\subsection{Plasma discharge temperatures}

The rotational temperature has been calculated from relative intensities of spectral line broadening of the (0-2) band structure of nitrogen second positive system $\mathrm{N}_{2}$ (C-B). The spectra are integrated over an exposure time of $100 \mathrm{~ns}$ following the starting of the voltage pulse with a slit width of $20 \mu \mathrm{m}$ and it is accumulated for 300,000 pulses to increase the measurement accuracy. The signal has been averaged over four entire holes of $0.4 \mathrm{~mm}$ diameter. The measurements are carried out for a methane-air mixture with an equivalence ratio of 0.5 , flow rate of $3.4 \mathrm{l} / \mathrm{min}$ and pulses repetition rate of $3 \mathrm{kHz}$ using a grating of 3600 grooves $/ \mathrm{mm}$. As shown in Fig. 7 (left), the rotational temperature of the discharge is determined by fitting the experimental spectra with the line-by-line radiation code SPECAIR [12] and convoluted with the measured instrumental slit function. The rotational temperature was found to be $480 \pm 50 \mathrm{~K}$ under the above-mentioned conditions.

The vibrational temperature of the plasma discharge was obtained by comparing the relative intensities of nitrogen second positive system $\mathrm{N}_{2}$ (C-B) with the SPECAIR simulation data. The measurements are done by using a grating of 1800 grooves $/ \mathrm{mm}$ which covers the following bands (0-2), (1-3), (2-4) of $\mathrm{N}_{2}$ (C-B). Like the rotational measurements, the signal is averaged over four complete holes and integrated over 100,000 pulses. As shown in Fig. 7 (right), the SPECAIR code shows a good agreement with a vibrational temperature of $3700 \pm 100 \mathrm{~K}$. This shows that the vibrational temperature, which is mainly driven by electron collisions, is considerably higher than the rotational temperature. This indicates a high average electron energy in the plasma discharge at this condition.

\subsection{Gas temperature}

In non-equilibrium plasmas at atmospheric pressure driven by nanosecond pulses, the rotational excitation requires low energy and short transition time. Therefore, a thermal equilibrium between molecules in rotational states and heavy molecules of the gas can be easily achieved [13]. Based on that, a translational temperature of $480 \mathrm{~K}$, which is the rotational temperature of the discharge as shown in the Section 3.2, can be assumed. Of course, this translational temperature is a time and location dependent, i.e. it exists only during the pulse duration and at the discharge location. In other words, the translational temperature is not necessarily to be equal to the average gas temperature.

To measure the average gas flow temperature, we used a shielded thermocouple type $\mathrm{K}$ (model Testo 0602) with $5 \mathrm{~mm}$ measurement head to damp fluctuations resulting from the strong electromagnetic field generated by the high-voltage discharge. The probe head is located $5 \mathrm{~mm}$ above the central hole of the plasma reactor. Fig. 8 shows the increase of the gas flow temperature as a function of pulse repetition frequency at a flow rate of $3.41 / \mathrm{min}$ and an equivalence ratio of 0.5 . The figure shows an average value of 6 degrees of temperature rise per $1 \mathrm{kHz}$ when the voltage across the electrodes is $5 \mathrm{kV}$.

This figure provides an average value of the thermal power generated by the plasma discharge $Q=\dot{m} . c . \Delta T$ equal to $0.42 \mathrm{~W}$ for $1 \mathrm{kHz}$ i.e., $0.42 \mathrm{~mJ} /$ pulse. This value is about $94 \%$ of the pulse energy calculated by the voltage and current measurements in Section 3.1. The remaining $6 \%$ of the consumed power is spent into other directions such as; (a) heating-up the dielectric material and part of this goes to the burner body by conduction, (b) some of the energy is spent in the so-called 'plasma buffer' as shown in Fig. 2A, which is a small surface plasma discharge work in parallel with the microplasma discharge to increase the lifetime of the reactor, and (c) a small fraction of the energy can be lost in the electromagnetic radiation generated by the reactor.

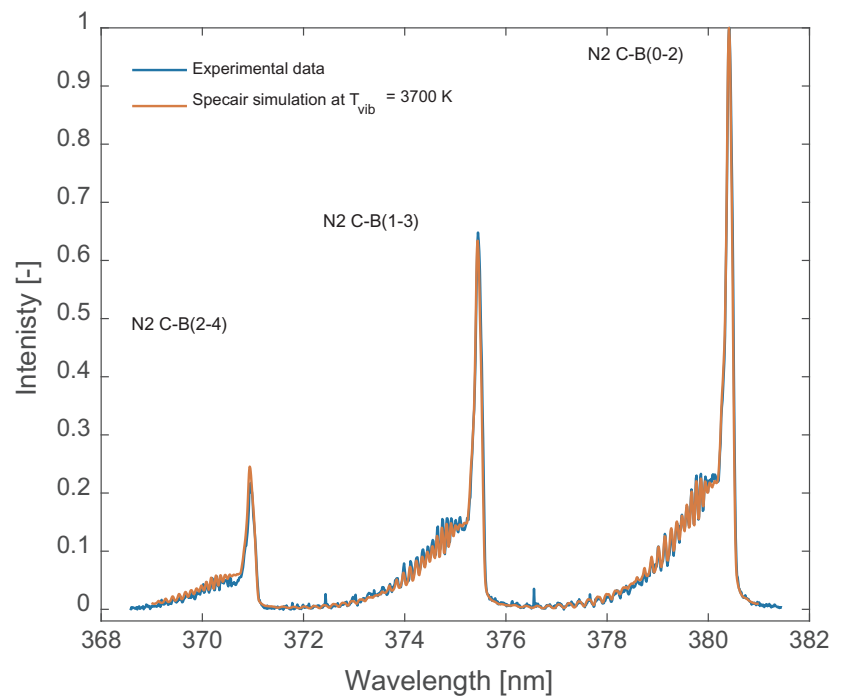

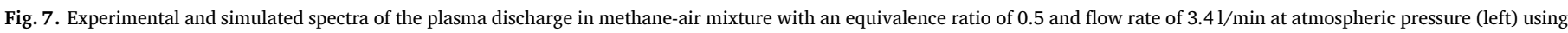
a 3600 grooves/mm grating, and (right) using an 1800 grooves/mm grating. 


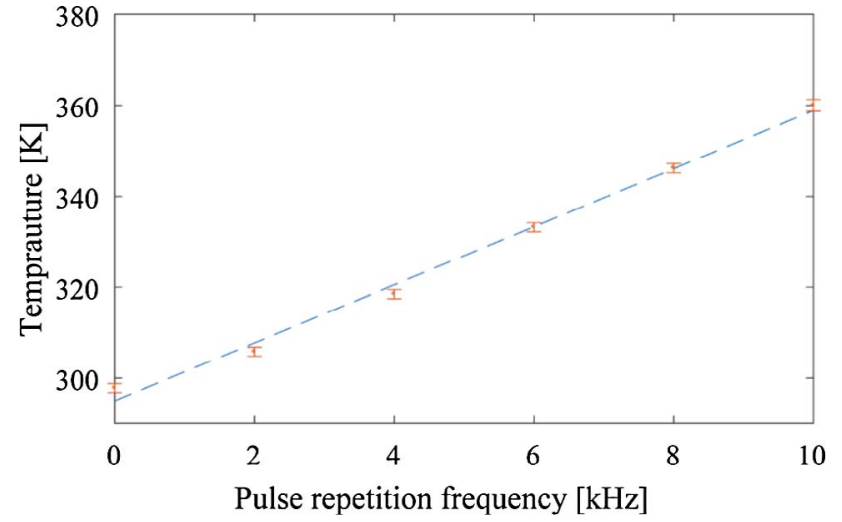

Fig. 8. The effect of discharge frequency on methane-air mixture temperature of a $3.4 \mathrm{l} /$ min gas flow rate, an equivalence ratio of 0.5 and a voltage of $5 \mathrm{kV}$ at atmospheric pressure.

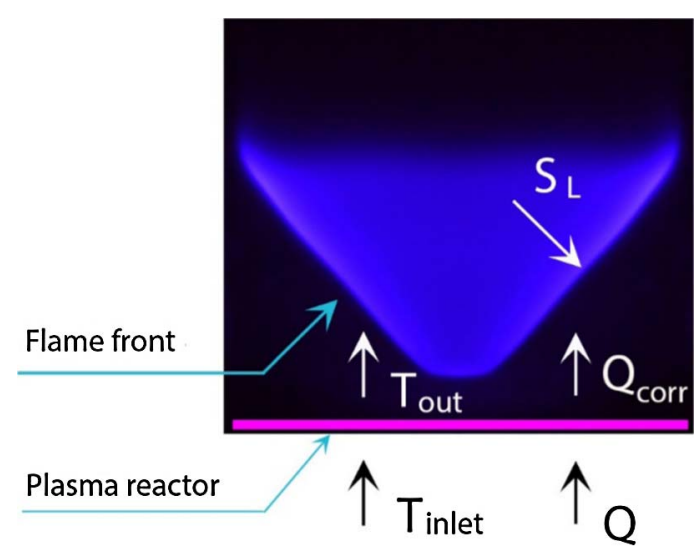

Fig. 9. Schematic of the flame area method to measure the laminar burning velocity $S_{L}$.

\subsection{Burning velocity measurements}

The main principle to determine the burning velocity is to measure the normal component to the flow velocity of the mixture at the flame front, which is supposed to be equal to the burning velocity of the gas mixture. The average burning velocity $S_{L}$ is calculated by dividing the gas mixture volume flow rate $Q$ by the conical area of the flame front A flame

$S_{L}=Q / A_{\text {flame }}$

To accurately determine the flame area, $\mathrm{CH}^{*}$ chemiluminescence images taken by Nikon camera model D5200 fitted with $50 \mathrm{~mm}$ focal length and a 10-nm bandpass filter (CVI Melles Griot F10-430.0-4$50.0 \mathrm{M}$ ) centred at $430 \mathrm{~nm}$ have been used. $\mathrm{A} \mathrm{CH}^{*}$ chemiluminescence analysis has been used to avoid the error in area calculation due to flame luminosity. Account is taken for the axial symmetry of the flame, as shown in Fig. 9.

This method has been validated by comparing the base-case results (without plasma discharge) with other published experimental and numerical (GRI-Mech 3.0) results on burning velocity for methane-air mixtures at atmospheric conditions, [14-18]. As shown in Fig. 10, the present experimental results are in a good agreement with the published data with a slight over-estimation at very lean conditions.

In the case of plasma discharge, a correction has been made for the volumetric flow rate calculation to account for the mixture thermal expansion due to plasma heating effect to the gas mixture, see Fig. 9.

$Q_{\text {corr }}=Q \cdot\left(T_{\text {out }} / T_{\text {in }}\right)$

where $Q_{\text {corr }}$ is the corrected flow rate, $Q$ is the inlet flow rate, $T_{\text {out }}$ is the mixture temperature downstream the reactor and $T_{\text {in }}$ is the inlet mixture temperature. $T_{\text {out }}$ is calculated based on the total consumed energy at the corresponding equivalence ratio, as shown in Fig. 6 .

To illustrate the effect of plasma discharge on the laminar burning velocity, Fig. 11 shows $\mathrm{CH}^{*}$ chemiluminescence images of methane-air premixed flames at different equivalence ratios, ranging from 0.55 to 0.75 , and plasma voltage of $5 \mathrm{kV}$ at atmospheric pressure and different

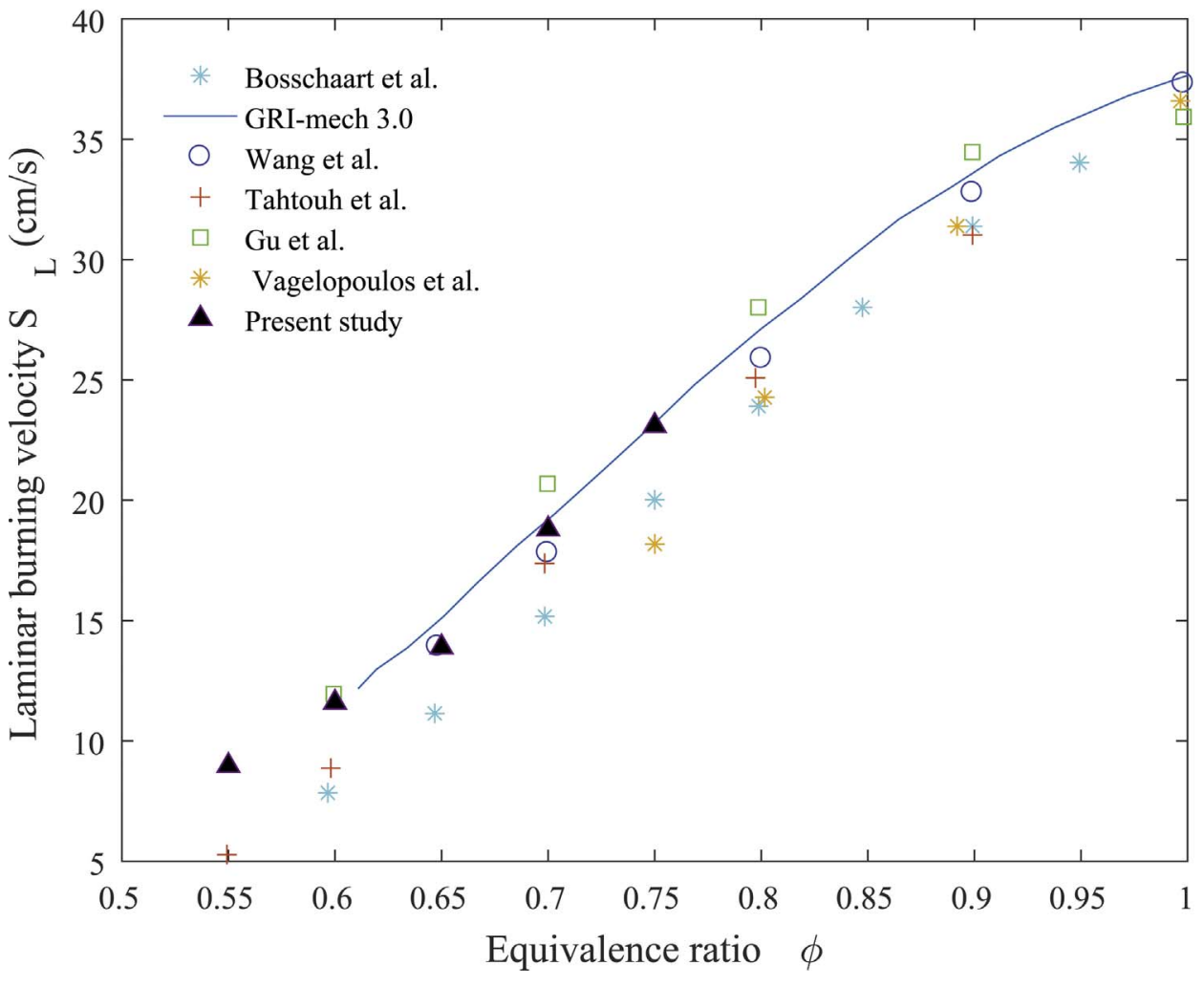

Fig. 10. Validation of laminar burning velocity measurements from the present study and published data for methane-air mixtures at $P=1 \mathrm{bar}$ and $T=300 \mathrm{~K}$. 


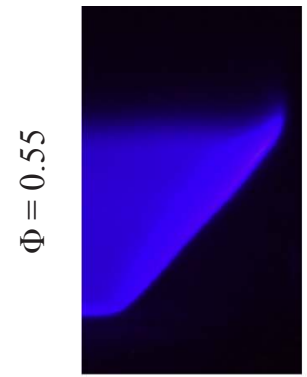

(a) $0 \mathrm{kHz}$

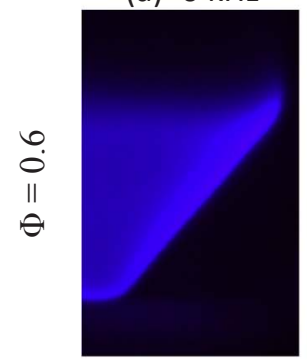

(g) $0 \mathrm{kHz}$

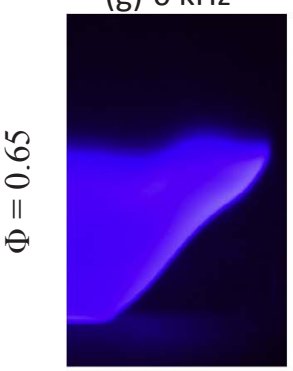

(m) $0 \mathrm{kHz}$

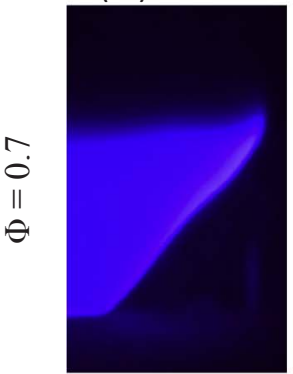

(s) $0 \mathrm{kHz}$

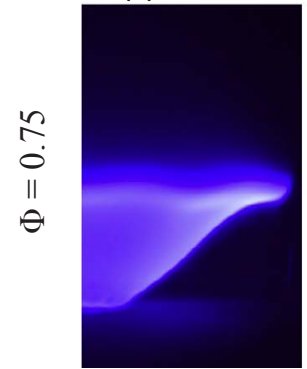

(y) $0 \mathrm{kHz}$

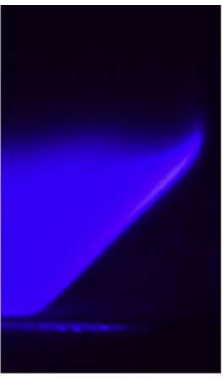

(b) $2 \mathrm{kHz}$

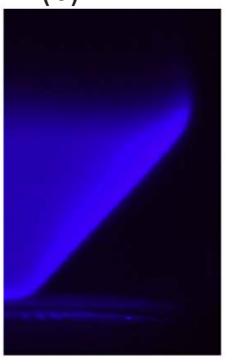

(h) $2 \mathrm{kHz}$

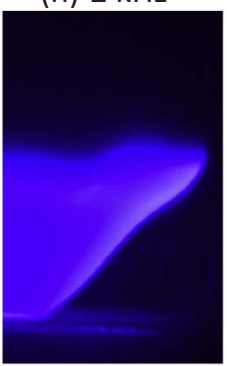

(n) $2 \mathrm{kHz}$

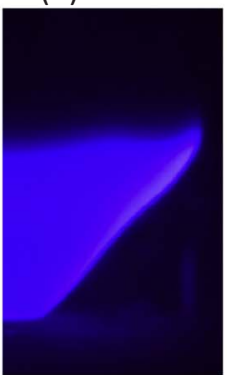

(t) $2 \mathrm{kHz}$

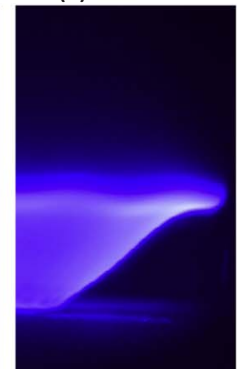

(z) $2 \mathrm{kHz}$

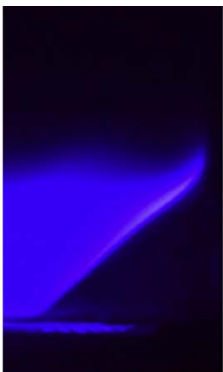

(c) $4 \mathrm{kHz}$

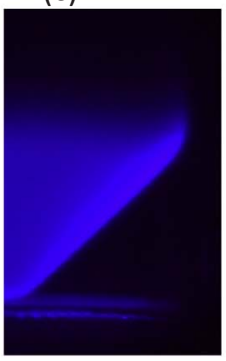

(i) $4 \mathrm{kHz}$

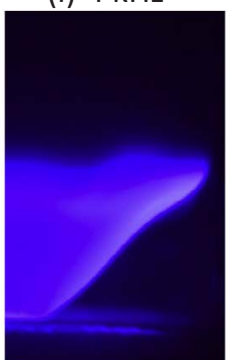

(o) $4 \mathrm{kHz}$

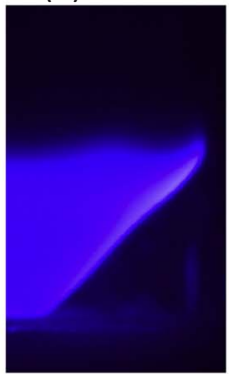

(u) $4 \mathrm{kHz}$

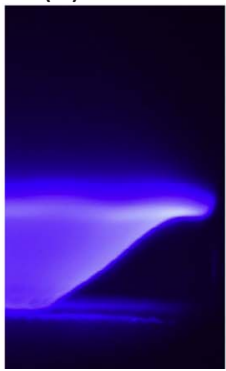

(aa) $4 \mathrm{kHz}$

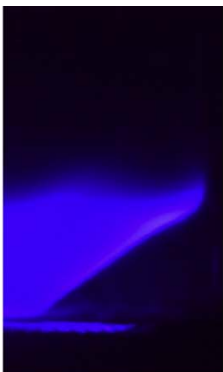

(d) $6 \mathrm{kHz}$

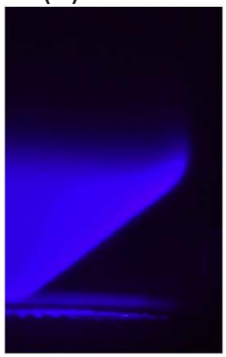

(j) $6 \mathrm{kHz}$

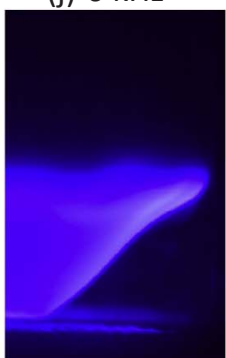

(p) $6 \mathrm{kHz}$

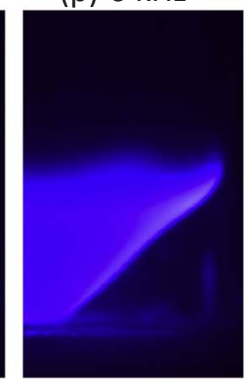

(v) $6 \mathrm{kHz}$

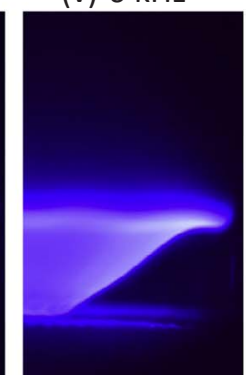

(bb) $6 \mathrm{kHz}$

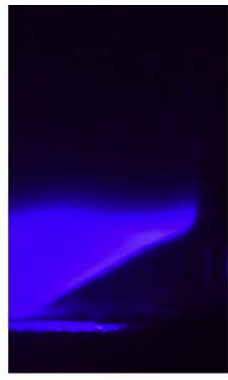

(e) $8 \mathrm{kHz}$

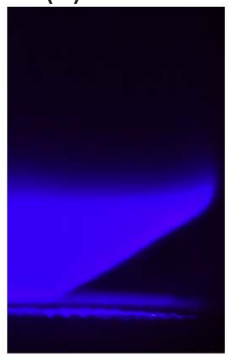

(k) $8 \mathrm{kHz}$

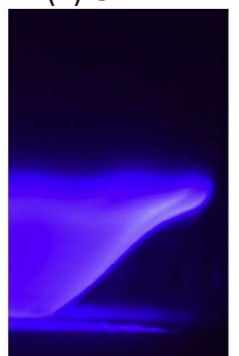

(q) $8 \mathrm{kHz}$

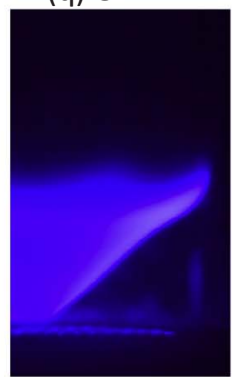

(w) $8 \mathrm{kHz}$

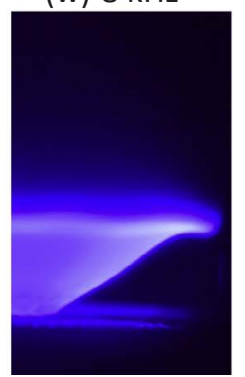

(cc) $8 \mathrm{kHz}$

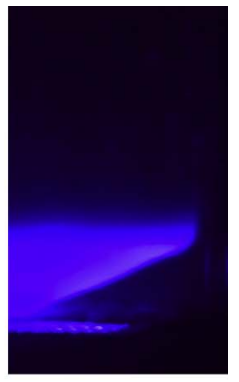

(f) $10 \mathrm{kHz}$

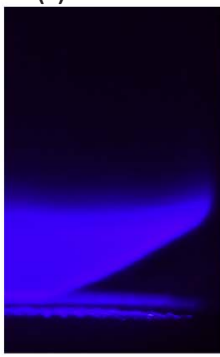

(I) $10 \mathrm{kHz}$

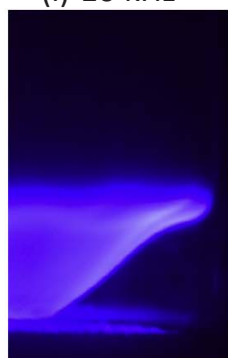

\section{(r) $10 \mathrm{kHz}$}

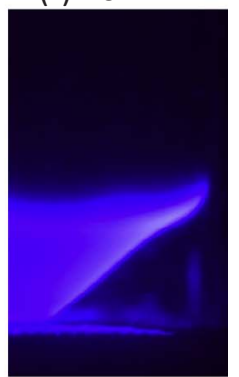

(x) $10 \mathrm{kHz}$

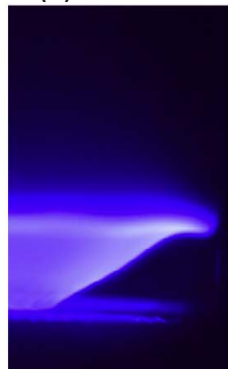

(dd) $10 \mathrm{kHz}$

Fig. 11. $\mathrm{CH}^{*}$ chemiluminescence images for methane-air flame at different pulse repetition rates and different equivalence ratios at atmospheric pressure and $\mathrm{V}=5 \mathrm{kV}$.

pulse repetition rates. For instance, at equivalence of 0.6 , and in the absence of plasma discharge, the flame has a conical shape, with a $5 \mathrm{~mm}$ base, anchored at the central position. The figure shows a reduction in the flame front area by $27 \%$ at a pulse repetition rate of $10 \mathrm{kHz}$. In this condition, an increase of $22 \%$ in the mixture flow rate as a result of the heating effect due to the plasma discharge has been considered. This shows an overall increase in the burning velocity of about $66 \%$. Table 1 shows the percentage of the plasma power to the flame power for methane-air flames at different equivalence ratios and pulse repetition rates.

Fig. 12 shows an overview on the effect of pulse repetition rate at different equivalence ratios on the laminar burning velocity of methane-air flames at atmospheric pressure and initial gas temperature of $300 \mathrm{~K}$ and voltage of $5 \mathrm{kV}$. The plasma discharge, promoted by the 
Table 1

Percentage of the plasma power to the flame power (\%) for methane-air flames at different equivalence ratios and pulse repetition rates.

\begin{tabular}{lllllll}
\hline \multirow{2}{*}{$\phi$} & Flow rate (l/min) & \multicolumn{6}{l}{ Pulse repetition rate $(\mathrm{kHz})$} \\
\cline { 3 - 7 } & & 2 & 4 & 6 & 8 & 10 \\
\hline 0.55 & 2.55 & 1.58 & 3.16 & 4.74 & 6.32 & 7.90 \\
0.60 & 3.40 & 1.06 & 2.13 & 3.19 & 4.25 & 5.31 \\
0.65 & 4.43 & 0.74 & 1.48 & 2.21 & 2.95 & 3.69 \\
0.70 & 5.45 & 0.54 & 1.09 & 1.63 & 2.18 & 2.72 \\
0.75 & 5.96 & 0.45 & 0.91 & 1.36 & 1.81 & 2.27 \\
\hline
\end{tabular}

thermal and chemical enhancement mechanism, was capable to increase the laminar burning velocity. This enhancement depends on the mixture equivalence ratio, discharge repetition rate, the flame power and the flame to plasma distance. These factors can also identify the relative weight of each mechanism to enhance the burning velocity. According to the figure, for very lean condition $(\Phi=0.55)$, plasma discharge was capable to increase the burning velocity from $8.5 \mathrm{~cm} / \mathrm{s}$ to $16.6 \mathrm{~cm} / \mathrm{s}$, which is about $100 \%$ enhancement, at pulse repetition rate of $10 \mathrm{kHz}$ by consuming $7.9 \%$ of flame power. At higher equivalence ratio, the influence of plasma on the burning velocity is less significant. For instance, at an equivalence ratio of ( $\Phi=0.75)$, the enhancement of laminar burning velocity at a pulse repetition rate of $10 \mathrm{kHz}$ is only about $26 \%$. We can explain this reduction of the plasma effect by two reasons. First, the plasma/flame power ratio decreases with increasing the equivalence ratio, as shown in Table 1 . Second, the reduction in the plasma species and radicals as a result of increasing the amount of fuel in the mixture, as mentioned later in Section 3.1.

To accurately define the main mechanism responsible for this enhancement, a CHEM1D code [19] has been used to simulate the burning velocity at the same conditions but with inlet mixture temperatures equal to those produced by the plasma discharge. Fig. 13 shows a comparison between the simulated (in red) and experimental results (in blue) for methane-air flames at an equivalence ratio of 0.6 . The results

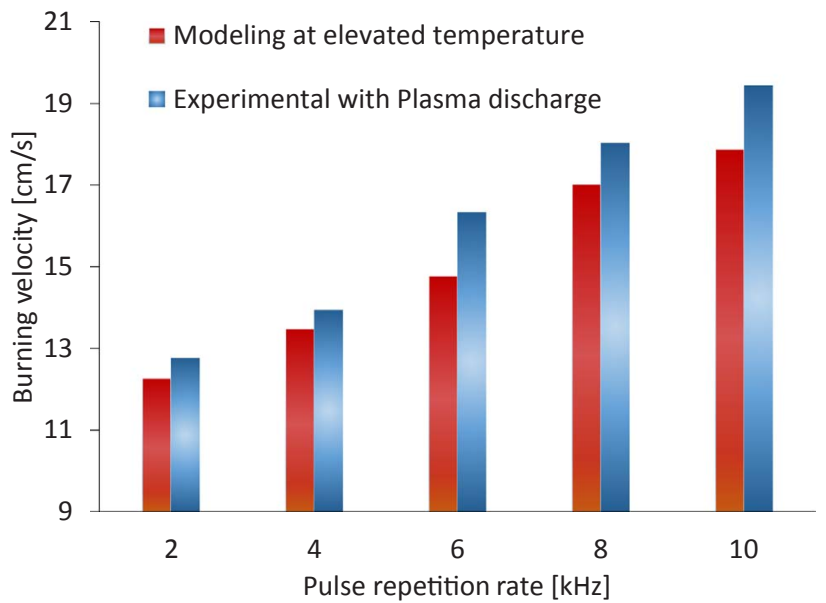

Fig. 13. A comparison between the effect of plasma discharge (in blue) and the simulated inlet mixture temperature (in red) on the burning velocity, for methane-air flames at an equivalence ratio of 0.6 .

indicate that the thermal effect of the plasma discharge is the dominating mechanism for the burning velocity enhancement. However, there is a small contribution (5-10\%) due to other mechanisms, like kinetic and transport, can be extracted from the difference between the experimental and simulation results. Moreover, one can notice that this difference is slightly higher at high repetition rates. This can be attributed to the higher background ionization level at high repetition rates, as reported by Nijdam et al. [20]. This high background ionization can increase the concentration of the long lifetime species, which may play a role in the increase of the burning velocity. More investigation is needed to address the species responsible for this behaviour and the effect of pulse repetition rate on the concentration of those species.

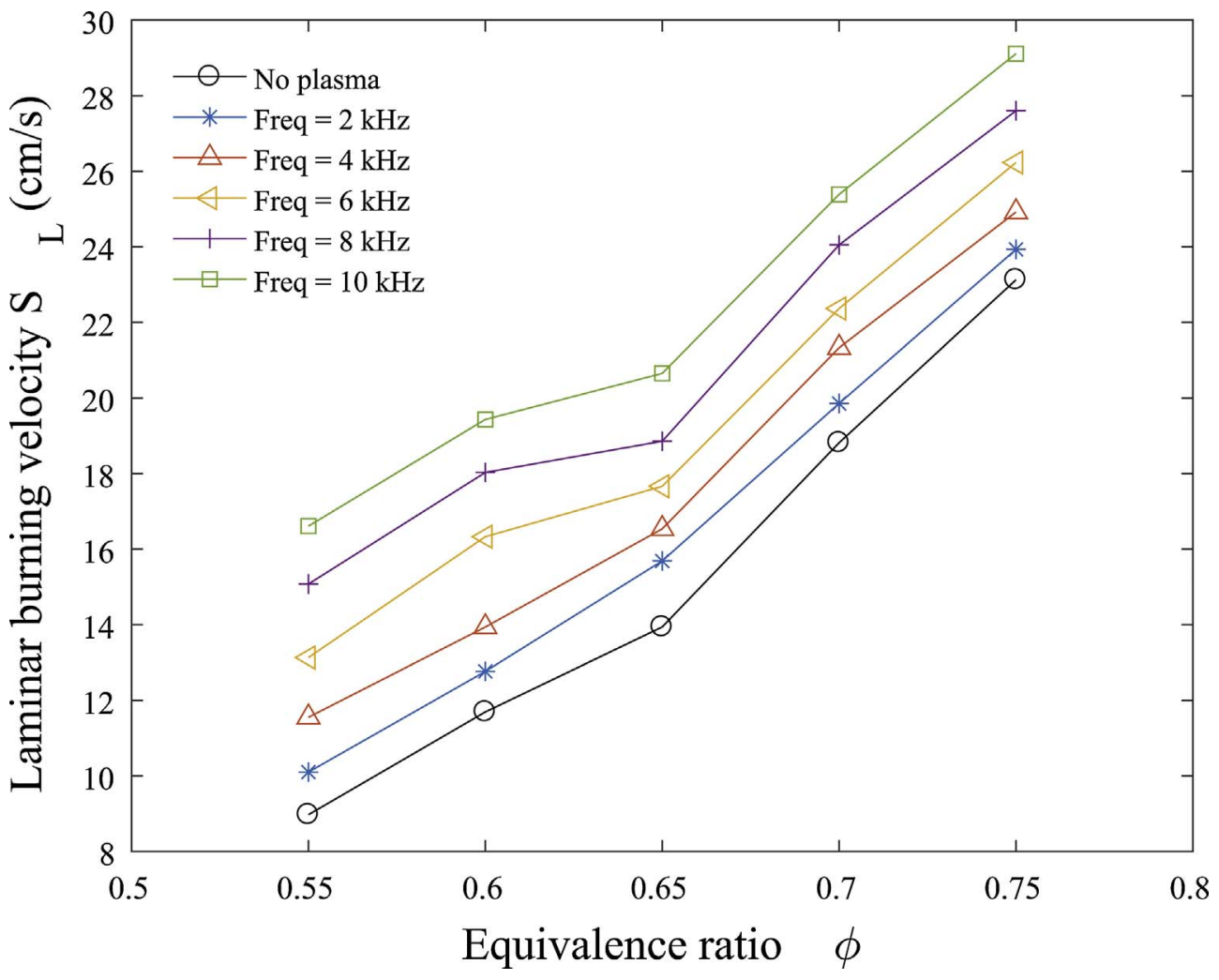

Fig. 12. Effect of pulse repetition rate on laminar burning velocity, calculated by the flame area method, for methane-air flames at different equivalence ratios at atmospheric pressure and $\mathrm{V}=5 \mathrm{kV}$. 


\section{Conclusion}

This paper presents a new burner configuration that utilizes a DBD microplasma reactor driven by nanosecond repetitively high voltage pulses. By this design, we are able to hold an inverted conical shape flame at lean condition on top of the reactor to study the effect of the non-thermal plasma discharge on the flame characteristics at atmospheric pressure.

Time evolution of the current and voltage have been measured simultaneously to calculate the pulse energy. A set of spectral analyses of nitrogen second positive system $\mathrm{N}_{2}$ (C-B) was done to characterize the vibrational and rotational temperatures of the plasma discharge. These measurements provide values of $480 \mathrm{~K}$ and $3700 \mathrm{~K}$ for the rotational and vibrational temperatures, respectively, by fitting the experimental results to SPECAIR simulation data. Average gas temperature, which represents a key parameter for the burning velocity enhancement, was measured. An average value of six degrees rise in the gas temperature per one $\mathrm{kHz}$ of pulse repetition rate for $3.4 \mathrm{l} / \mathrm{min}$ of gas flow was found. This indicates that a value of $0.42 \mathrm{~mJ} /$ pulse of pulse energy is transferred to the gas as thermal energy.

An experiment to measure the laminar burning velocity has been done using the flame area method. $\mathrm{CH}^{*}$ chemiluminescence image analysis has been used to accurately determine the flame area. The results show that the increase in the burning velocity depends on a number of factors, namely, equivalence ratio, pulse repetition rate, and plasma to flame power ratio. Finally, a comparison between the experimental and numerical results reveal that about $90 \%$ of the burning velocity enhancement is due to the increase in the mixture temperature as a result of the plasma discharge.

\section{Acknowledgment}

A. Elkholy is supported by a Ph.D. grant from the Ministry of Higher Education, Government of Egypt.

\section{References}

[1] W. Kim, M.G. Mungal, M.A. Cappelli, The role of in situ reforming in plasma enhanced ultra-lean premixed methane/air flames, Combust. Flame 157 (2) (2010)
374-383

[2] D.A. Lacoste, D.A. Xu, J.P. Moeck, C.O. Laux, Dynamic response of a weakly turbulent lean-premixed flame to nanosecond repetitively pulsed discharges, Proc. Combust. Inst. 34 (2) (2013) 3259-3266.

[3] Y.H. Choi, J.H. Kim, K.H. Paek, W.T. Ju, Y.S. Hwang, Characteristics of atmospheric pressure N2 cold plasma torch using $60-\mathrm{Hz}$ AC power and its application to polymer surface modification, Surface and Coatings Technology, 193 (1-3) (2005), pp. 319324.

[4] Y.D. Korolev, I.B. Matveev, Nonsteady-state processes in a plasma pilot for ignition and flame control, IEEE Trans. Plasma Sci. 34 (6) (2006) 2507-2513.

[5] R. Stonies, S. Schermer, E. Voges, J.A.C. Broekaert, A new small microwave plasma torch, Plasma Sources Sci. Technol. 13 (4) (2004).

[6] T.J. Bonazza, K.L. Van Voorhies, J.E. Smith, Rf plasma ignition system concept for lean burn internal combustion engines, SAE Technical Paper No. 929416, 1992.

[7] M.M. Moselhy, K.H. Schoenbach, Nanosecond pulse generators for microdischarge excimer lamps, in: 14th IEEE International IEEE, 2003, pp. 1317-1320.

[8] T. Li, I.V. Adamovich, J.A. Sutton, Effects of non-equilibrium plasmas on lowpressure, premixed flames. Part 1: $\mathrm{CH}^{*}$ chemiluminescence, temperature, and $\mathrm{OH}$, Combust. Flame 165 (2016) 50-67.

[9] A.P. Papadakis, S. Rossides, A.C. Metaxas, Microplasmas: a review, Open Appl. Phys. J. 4 (1) (2011).

[10] O. Sakai, Y. Kishimoto, K. Tachibana, Integrated coaxial-hollow micro dielectricbarrier-discharges for a large-area plasma source operating at around atmospheric pressure, J. Phys. D Appl. Phys. 38 (3) (2005) 431.

[11] G. Pilla, D. Galley, D.A. Lacoste, F. Lacas, D. Veynante, C.O. Laux, Stabilization of a turbulent premixed flame using a nanosecond repetitively pulsed plasma, IEEE Trans. Plasma Sci. 34 (2006) 2471-2477.

[12] C.O. Laux, T.G. Spence, C.H. Kruger, R.N. Zare, Optical diagnostics of atmospheric pressure air plasmas, Plasma Sources Sci. Technol. 12 (2) (2003) 125.

[13] A. Chelouah, E. Marode, G. Hartmann, S. Achat, A new method for temperature evaluation in a nitrogen discharge, J. Phys. D Appl. Phys. 27 (5) (1994) 940.

[14] Z. Wang, L. Yang, B. Li, Z. Li, Z. Sun, M. Alden, K. Cen, A. Konnov, Investigation of combustion enhancement by ozone additive in $\mathrm{CH}_{4}$ /air flames using direct laminar burning velocity measurements and kinetic simulations, Combust. Flame 159 (1) (2012) 120-129.

[15] K. Bosschaart, L. de Goey, Detailed analysis of the heat flux method for measuring burning velocities, Combustion and Flame, 132 (1-2) (2003), pp.170-180.

[16] X. Gu, M. Haq, M. Lawes, R. Woolley, Laminar burning velocity and Markstein lengths of methane-air mixtures, Combust. Flame 121 (2000) 41-58.

[17] C.M. Vagelopoulos, F.N. Egolfopoulos, Direct experimental determination of laminar flame speeds, Symp. (Int.) Combust. 27 (1998) 513-519.

[18] T. Tahtouh, F. Halter, C. Mounaim-Rousselle, Measurement of laminar burning speeds and Markstein lengths using a novel methodology, Combust. Flame 156 (2009) 1735-1743.

[19] L.M.T. Somers, The Simulation of Flat Flames With Detailed And Reduced Chemical Models, PhD thesis Technische Universiteit Eindhoven, The Netherlands, 1996.

[20] S. Nijdam, G. Wormeester, E.M. van Veldhuizen, U. Ebert, Probing background ionization: positive streamers with varying pulse repetition rate and with a radioactive admixture, J. Phys. D Appl. Phys. 44 (45) (2011). 